\title{
Clinical utility of fixed-dose combinations in hypertension: evidence for the potential of nebivolol/valsartan
}

This article was published in the following Dove Press journal:

Integrated Blood Pressure Control

26 November 2014

Number of times this article has been viewed

\author{
Jasmina Varagic ${ }^{1-3}$ \\ Henry Punzi ${ }^{4,5}$ \\ Carlos M Ferrario $2,3,6$ \\ 'Hypertension and Vascular Research \\ Center, ${ }^{2}$ Division of Surgical \\ Sciences, ${ }^{3}$ Department of Physiology \\ and Pharmacology, Wake Forest \\ University, Winston-Salem, NC USA; \\ ${ }^{4}$ Trinity Hypertension and Diagnostic \\ Research Center, Carrollton, TX, \\ USA; ${ }^{5}$ Department of Family and \\ Community Medicine, University of \\ Texas Southwestern Medical Center, \\ Dallas, TX, USA; ${ }^{6}$ Department of \\ Internal Medicine and Nephrology, \\ Wake Forest University, Winston- \\ Salem, NC, USA
}

\begin{abstract}
Despite significant advances in pharmacologic approaches to treat hypertension during the last decades, hypertension- and hypertension-related organ damage are still a high health and economic burden because a large proportion of patients with hypertension do not achieve optimal blood pressure control. There is now general agreement that combination therapy with two or more antihypertensive drugs is required for targeted blood pressure accomplishment and reduction of global cardiovascular risk. The goals of combination therapies are to reduce long-term cardiovascular events by targeting different mechanism underlying hypertension and target organ disease, to block the counterregulatory pathways activated by monotherapies, to improve tolerability and decrease the adverse effects of up-titrated single agents, and to increase persistence and adherence with antihypertensive therapy. Multiple clinical trials provide evidence that fixed-dose combinations in a single pill offer several advantages when compared with loose-dose combinations. This review discusses the advances in hypertension control and associated cardiovascular disease as they relate to the prospect of combination therapy targeting a third-generation beta $(\beta)$ 1-adrenergic receptor (nebivolol) and an angiotensin II receptor blocker (valsartan) in fixed-dose single-pill formulations.
\end{abstract}

Keywords: blood pressure control, hypertension, $\beta 1$-adrenergic receptor, renin angiotensin system, fixed-dose combination therapy, nebivolol, valsartan

\section{Introduction}

Hypertension, having a high prevalence worldwide, ${ }^{1,2}$ is estimated to affect approximately 78 million persons in the United States. ${ }^{3,4}$ Although high blood pressure (BP) is recognized as an important cardiovascular risk factor for the development of coronary heart disease and stroke, ${ }^{5}$ effective hypertension control can reduce heart failure (HF) incidence by $50 \%{ }^{6}$

Despite increased awareness of both patients and physicians as to the consequences of uncontrolled BP and the availability of new pharmacologic approaches to treat hypertension during the last decades, ${ }^{7}$ hypertension-related and, consequently, hypertensionrelated organ damage still make up a high health and economic burden because a large proportion of patients with hypertension do not achieve optimal BP control. Thus, there is an imperative for efficient control of hypertension, as the economic burden to society associated with hypertension was estimated to a have cost of US\$73.4 billion in 2009. ${ }^{8}$ Although numerous initiatives from the medical community across the world continue to adjust guidelines and policies to assist in hypertension prevention, detection, and treatment, ${ }^{6}$ the need for focus management of hypertension and its associated risk factors using appropriate medicines and effective comanagement of cardiometabolic
Correspondence: Jasmina Varagic Hypertension and Vascular Research Center, Division of Surgical Sciences, Wake Forest University School of Medicine, Medical Center Boulevard, Winston-Salem, NC 27I57, USA

$\mathrm{Tel}+\mathrm{I} 3367162738$

Fax +I 3367160269

Email jvaragic@wfubmc.edu
Integrated Blood Pressure Control 20| 4:7 6I-70 
risk factors remains unattained. ${ }^{9,10}$ This review discusses the advances in hypertension control and associated cardiovascular $(\mathrm{CV})$ disease as they relate to the prospect of combination therapy targeting beta $\left(\beta_{1}\right)$-adrenergic receptor (nebivolol) and the renin angiotensin system (RAS), angiotensin II (Ang II) type 1 receptor (valsartan) in fixed-dose single pill.

\section{BP control/cardiovascular risks/target organ diseases: a need for combination therapy}

An emerging view suggests that hypertension results from an imbalance between vasoconstrictor and vasodilatory mechanisms of diverse hormonal, neurogenic, and local vascular nature. ${ }^{11,12}$ The heterogeneous, often timedependent, contribution of altered mechanisms influencing BP and, hence, tissue perfusion, accounts for the successful development and availability of classes of pharmacological options: thiazide and thiazide-like diuretics, selective $\left(\beta_{1}^{-}\right)$ and alpha $(\alpha-)$ adrenergic receptor blockers, calcium channel blockers (CCBs), various drugs inhibiting RAS components (ie, direct renin inhibitors, angiotensin converting enzyme inhibitors [ACEIs], and Ang II receptor blockers [ARBs]), and vasodilators. To achieve optimal BP control, the Seventh Report of the Joint National Committee on Prevention, Detection, Evaluation, and Treatment of High Blood Pressure $(\mathrm{JNC} 7)^{13}$ endorses the use of combination therapy rather than increasing the dose of an agent. Although approaches geared toward the prevention of hypertension and its clinical complications through lifestyle modifications, increased physical activity, and dietary changes are critically important, antihypertensive therapy will continue to be the mainstay of therapy.

There is now general agreement that monotherapy is less likely to be sufficient to achieve optimal BP control in a majority of patients, ${ }^{13,14}$ and combination therapy with two or more antihypertensive drugs is usually required for targeted $\mathrm{BP}$ accomplishment and reduction of $\mathrm{CV}$ risk. ${ }^{15,16}$ Moreover, according to JNC 7 guidelines ${ }^{13}$ and the guidelines put forth jointly by the International Society of Hypertension and the European Society of Hypertension, ${ }^{17,18}$ BP-lowering treatment should be initiated with a combination of two drugs in patients with a systolic pressure higher than $20 \mathrm{mmHg}$ and/ or a diastolic pressure higher than $10 \mathrm{mmHg}$ of the targeted goal, as well as in the patients with multiple CV risk factors such as metabolic syndrome, diabetes, and heart and renal disease. The recommendation to target multiple pathophysiological mechanisms underlying the development and progression of hypertension using combination therapy of two or more complementary, yet distinct, drugs is supported by the evidence that in comparison with monotherapy, combination therapy raises the probability of achieving a BP target in a shorter amount of time, ${ }^{13,19}$ and combination therapy is several times more potent than increasing the dose of the single drug. ${ }^{20-22}$

Indeed, the use of combination therapy at diagnosis contributed to a greater $\mathrm{CV}$ risk reduction when compared with monotherapy. ${ }^{21}$ According to a global survey conducted by the International Society of Hypertension, ${ }^{23}$ the preferred combination across different countries is RAS inhibition combined with CCB (particularly for the patients with type 2 diabetes) or diuretics. The successful combination of drugs also reflects the ability of the components to block the counterregulatory pathways activated by each other. Thus, when CCBs and diuretics activate RAS, the addition of RAS inhibitors will offer more favorable outcomes for the combination therapy than for $\mathrm{CCB}$ or diuretics alone. Undeniably, convincing evidence from large clinical studies such as the Avoiding Cardiovascular Events Through Combination Therapy in Patients Living with Systolic Hypertension (ACCOMPLISH), ${ }^{24}$ the Valsartan Antihypertensive Long-term Use Evaluation (VALUE), ${ }^{25}$ the Action in Diabetes and Vascular Disease: Preterax and Diamicron MR Controlled Evaluation (ADVANCE), ${ }^{26}$ and the Perindopril Protection Against Recurrent Stroke Study (PROGRESS) ${ }^{27}$ trials clearly support the use of combination therapies to initiate antihypertensive treatment. An additional rationale for combination regimes is based on improved tolerability and decreased adverse effects of up-titrated single agents. In addition to combination therapy given separately, fixed-dose combinations (FDCs) in a single pill offer several advantages reflected in greater adherence and improved treatment outcomes when compared with loose-dose combinations. ${ }^{28-30}$

\section{$\beta$-blockers in hypertension management}

Increased sympathetic nervous system activity is a major contributor to the development and progression of hypertension. ${ }^{31}$ Agents that block cardiac $\beta$-adrenergic receptors have been used as an alternative approach to diuretics for the initial treatment of hypertension in many countries for years. ${ }^{32}$ However, evidence from a recent meta-analysis suggests that $\beta$-blockers, apart from coronary heart disease, are less effective in preventing $\mathrm{CV}$ disease, particularly in the elderly. Thus, they are no longer regarded as first-choice drugs in the treatment of elderly patients or patients with metabolic syndrome, diabetes, or renal disease ${ }^{33-35}$ Although the panelists appointed to the Eighth Joint National Committee (JNC 8) ${ }^{36}$ 
did not recommend the use of $\beta$-blockers, specifically atenolol or metoprolol, for the initial treatment of hypertension on the basis of the results obtained in the Losartan Intervention for Endpoint Reduction in Hypertension (LIFE) Study, ${ }^{37}$ we directly quote the JNC statement acknowledging that "[...] compared a $\beta$-blocker to the 4 recommended drug classes, the $\beta$-blocker performed similarly to the other drugs (question 3, evidence statement 8) or the evidence was insufficient to make a determination (question 3, evidence statements $7,12,21,23$, and 24)." ${ }^{\prime 36}$ The exclusion of primarily atenolol for initial hypertension treatment was based on the results obtained in the Antihypertensive and Lipid-Lowering Treatment to Prevent Heart Attack (ALLHAT) Trial, ${ }^{38}$ but even in this situation, the conclusion is muddied by the fact that most patients assigned to the chlorthalidone group of the study received a $\beta$-blocker as the second drug for appropriate BP control. These limitations do not apply to the more advanced cases of hypertension with concomitant comorbidities, particularly HF. Thirty-nine years after Waagstein's original report of the beneficial effects of $\beta$-blockers in $\mathrm{HF}^{39}{ }^{39}$ these agents have become a well-established treatment component of HF management. This is an important consideration, as HF admissions to community hospitals pose a significant burden to the health care system, given the fact that readmission rates average 90 days postdischarge and 30-day mortality rates remain quite high. ${ }^{40}$

$\beta$-blockers are a heterogeneous class of drugs consisting of agents with different adrenergic receptor selectivity, lipophilicity, and intrinsic sympathomimetic activity, as well as vasodilatory and antioxidant properties (Table 1). Thus, the BP-lowering effect of traditional $\beta$-blockers with no vasodilatory ability (ie, atenolol, metoprolol, propranolol) is achieved through a decrease in central nervous system sympathetic outflow, ${ }^{31}$ reduced cardiac output consequent to decreased heart rate and contractility, and reduced renin release. ${ }^{41}$ The magnitude of the antihypertensive response may be offset by compensatory vasoconstriction in the peripheral vasculature ${ }^{31,42}$ and negative effects on metabolic parameters and lipid profile, ${ }^{43}$ as well as increased venous return mediated by $\beta_{2}$-adrenergic receptor blockade enlarging the left ventricle..$^{42}$

Recent advances in the development of $\beta$-blockers led to the introduction of agents with additional vasodilatory abilities resulting from their concomitant blockade of $\alpha_{1}$-adrenergic receptors (labetalol, carvedilol) or the intriguing action of nebivolol in stimulating vascular endothelium-mediated release of nitric oxide (NO). Nebivolol is a racemic mixture of $\mathrm{D}$ - and L-enantiomers. D-nebivolol is responsible for $\beta_{1}$-antagonistic properties, whereas both
Table I Primary characteristics of $\beta$-adrenergic receptors

\begin{tabular}{|c|c|c|c|}
\hline Characteristic & $\begin{array}{l}\beta_{1} \text {-adrenergic } \\
\text { receptor }\end{array}$ & $\begin{array}{l}\beta_{2} \text {-adrenergic } \\
\text { receptor }\end{array}$ & $\begin{array}{l}\beta_{3} \text {-adrenergic } \\
\text { receptor }\end{array}$ \\
\hline $\begin{array}{l}\text { Number of } \\
\text { amino acids }\end{array}$ & 477 & 413 & 408 \\
\hline Introns & - & - & 2 \\
\hline $\begin{array}{l}\text { Phosphorylation } \\
\text { by pkA and } \beta A R K\end{array}$ & Yes & Yes & No \\
\hline $\begin{array}{l}\text { Most potent } \\
\text { catecholamine }\end{array}$ & Norepinephrine & Epinephrine & Norepinephrine \\
\hline $\begin{array}{l}\text { Selective } \\
\text { agonists }\end{array}$ & $\begin{array}{l}\text { Xamoterol, } \\
\text { dobutamine }\end{array}$ & $\begin{array}{l}\text { Zinterol, } \\
\text { procaterol }\end{array}$ & $\begin{array}{l}\text { BLR } 37344, \\
\text { CGP } 12 \mid 77\end{array}$ \\
\hline Selective & CGP 207I2A & ICl II855I & SR 59230A \\
\hline antagonists & Metoprolol & & \\
\hline $\mathrm{G}$ protein & Gs & $\mathrm{Gs} / \mathrm{Gi}$ & $\mathrm{Gs} / \mathrm{Gi}$ \\
\hline Effector & $\begin{array}{l}\text { Adenylate } \\
\text { cyclase }\end{array}$ & $\begin{array}{l}\text { Adenylate } \\
\text { cyclase }\end{array}$ & $\begin{array}{l}\text { Adenylate } \\
\text { cyclase, NO } \\
\text { synthase }\end{array}$ \\
\hline
\end{tabular}

Note: Copyright @2004. Medicina (Kaunas). Reproduced from Skeberdis VA. Structure and function of $\beta_{3}$-adrenergic receptors. Medicina. 2004;40(5)407-413. ${ }^{122}$

Abbreviations: pkA, protein kinase A; $\beta A R K$, beta-adrenergic receptor kinase; NO, nitric oxide.

D- and L-nebivolol activate NO synthase (NOS) predominantly through $\beta_{3}$ agonist activation. ${ }^{44}$ In addition, nebivolol can increase NO bioavailability by decreasing levels of asymmetric dimethylarginine, an endogenous inhibitor of NOS, which elevated levels in plasma are shown to correlate with endothelial dysfunction in different $\mathrm{CV}$ diseases ${ }^{45}$ and/or by its antioxidant properties targeting nicotinamide adenine dinucleotide phosphate-oxidase ${ }^{46}$ or more directly scavenging reactive oxygen species. ${ }^{47,48}$ Moreover, nebivolol offers additional protective effects on endothelial dysfunction and vascular remodeling with supplementary antiinflammatory properties $^{49}$ associated with neutral effects on metabolic parameters in patients with hypertension. ${ }^{50}$ In contrast to traditional $\beta$-blockers, nebivolol preserves cardiac output ${ }^{51}$ and reduces central aortic BP. ${ }^{52}$ Maintenance of cardiac output is related to the mild effects of the drug on heart rate coupled with the unique ability of this drug to induce peripheral venodilation, thus maintaining venous return..$^{53}$ It has been also shown that nebivolol, but not metoprolol, improved left ventricular dysfunction in an experimental model of myocardial infarction ${ }^{54}$ and that these cardioprotective effects may be mediated by $\beta_{3}$-receptors and $\operatorname{NOS}^{55}$ not only on the coronary vessels but also on the cardiac myocytes as well. Nebivolol also improves diastolic dysfunction and myocardial remodeling in Ang II-dependent hypertension, ${ }^{46}$ as well as in an obese insulin-resistant rodent model..$^{56}$ These later findings are of particular relevance, as left ventricular diastolic dysfunction, prevalent in hypertensive women, has proven highly resistant to treatment with ACEIs or even ARBs. ${ }^{40}$ 
Studies in animal models show that nebivolol augments vascular NO release, ${ }^{57}$ and data obtained from individuals with essential hypertension indicate that nebivolol treatment dilates forearm vasculature ${ }^{58}$ and reverses endothelial dysfunction. ${ }^{59}$ Nebivolol has also been shown to reduce QT dispersion in hypertensive patients with left ventricular hypertrophy after 4 weeks of treatment, an effect that did not correlate with BP reduction. ${ }^{60}$

The beneficial action of nebivolol in terms of facilitating production/release of NO may account for the observation that sexual dysfunction is not observed in male patients medicated with this drug. In one study, atenolol resulted in sexual dysfunction in $12.8 \%$ of patients compared with $3 \%$ of placebo-treated patients. ${ }^{61}$ A second study found that atenolol was associated with sexual dysfunction in $17.3 \%$ of patients compared with $3 \%$ of lisinopril-treated patients. ${ }^{62}$ The effects of 12 weeks of therapy with nebivolol $5 \mathrm{mg}$ once daily or metoprolol succinate $95 \mathrm{mg}$ on sexual function in stage 1 hypertensive men were studied in a double-blind, randomized crossover study. ${ }^{63}$ The primary endpoint at the end of each 12 week treatment period was the assessment of changes in the International Index of Erectile Function. The index is a reliable, validated, and widely used assessment scale in most trials evaluating erectile function. At the end of the 12 week period and before crossover to the other drug, the erectile function subscore showed no significant changes from baseline in male patients with stage 1 hypertension who were treated with nebivolol, whereas the results for the mean changes from baseline of all secondary efficacy criteria derived from the International Index of Erectile Function (orgasmic function, sexual desire, intercourse satisfaction, and overall satisfaction subscores) favored nebivolol. ${ }^{63}$ An additional study in which patients were assigned to the combination of chlorthalidone/atenolol, atenolol, or nebivolol only confirmed the essential lack of sexual dysfunction in only those patients who were randomized to nebivolol $5 \mathrm{mg}$ daily. ${ }^{64}$ Moreover, when nebivolol was compared with losartan, there was no difference in their effects on sexual function. ${ }^{65}$

In the United States, nebivolol has been approved for the treatment of stage 1-2 hypertension, and in Europe and many countries around the world, it has been approved for the treatment of HF as well. The efficacy and tolerability of nebivolol monotherapy in patients with hypertension have been demonstrated in three pivotal phase 3 trials ${ }^{66-68}$ results of another phase 3, randomized, double-blind, placebo-controlled trial in patients with stage 1-2 hypertension suggest that nebivolol, when added to an ongoing treatment with an ACEI, ARB, or diuretic, further lowers $\mathrm{BP}$ and improves $\mathrm{BP}$ response rate. ${ }^{69}$ A large German observational postmarketing study, carried out in 6,376 individuals with hypertension (mean systolic BP/diastolic BP, 173/101 mmHg; CV disease, $26.3 \%$; diabetes, $20.3 \%$; left ventricular hypertrophy, $20.4 \%$; HF, 9.1\%), demonstrated that a 6-week treatment with nebivolol resulted in DBP normalization $(<90 \mathrm{mmHg})$ in $62.2 \%$ of the patients. ${ }^{70}$ The beneficial action of nebivolol in reducing central BP suggests improvement in vascular compliance $50,52,71,72$ that may be related to the observations that the drug can reverse cardiac and vascular fibrosis.

Nebivolol is a safe and effective treatment for elderly patients with HF improving diastolic function and reducing mortality. ${ }^{73-76}$ In addition, at doses of 5-20 mg/day, nebivolol is very well tolerated. Higher doses of $40 \mathrm{mg} /$ day were associated with more adverse effects, probably because of loss of selectivity for $\beta_{1}$ receptors. Thus, in addition to better tolerability and greater persistence, ${ }^{77}$ this novel $\beta$-blocker may be particularly useful in difficult-to-treat patients such as African Americans (5-40 mg/day dose range), ${ }^{67}$ elderly patients $(5 \mathrm{mg} / \mathrm{d}),{ }^{52,78}$ and Hispanics ${ }^{79}$ with hypertension. Their favorable hemodynamic effect in reducing peripheral vascular resistance, rather than cardiac output, may account for the absence of fatigue as a significant adverse reaction to the drug. An obese patient with HF is expected to show some level of fatigue, and fatigue has frequently been considered to be associated with $\beta$-blocker treatment. ${ }^{80,81}$ However, a 2002 meta-analysis of randomized trials of $\beta$-blockers used in the treatment of myocardial infarction, hypertension, and HF demonstrated a statistically significant, yet small, annual risk for fatigue that was equivalent to one additional report per 57 patients treated with a $\beta$-blocker, with the effect being more pronounced with older-generation $\beta$-blockers. ${ }^{81}$ A similar meta-analysis that looked at HF trials only failed to demonstrate an absolute risk for fatigue associated with $\beta$-blocker treatment. ${ }^{80}$ At the time of these meta-analyses, no nebivolol trial satisfying the inclusion criteria (randomized, placebo-controlled studies with at least 100 enrolled patients and a noncrossover design) was completed, but no participants in the 8 month study involving elderly subjects with HF $(\mathrm{N}=260)^{82}$ reported fatigue, and in the 2-year trial involving the elderly with $\mathrm{HF}(\mathrm{N}=2,128)$, fatigue was reported by $6.7 \%$ nebivolol-treated and 5.8\% placebo-treated participants. ${ }^{73}$ In the three pivotal US trials of nebivolol (12 weeks, total enrollment of 2,016 patients), ${ }^{66,67,83}$ no nebivolol-treated individual reported fatigue as an adverse event. There is currently a study underway (ClinicalTrials.gov NCT00999102) designed to explicitly examine the effects of nebivolol and metoprolol 
on fatigue and quality of life, which should provide helpful clinical evidence regarding the risk for fatigue with these two $\beta$-blockers.

\section{Rationale for nebivolol/valsartan fixed- dose combination}

It is well known that Ang II exerts its vasoconstrictor/ hypertrophic/profibrotic effects by activating $\mathrm{AT}_{1}$ receptors on vasculature, heart, and kidneys. In this way, Ang II acts as a major contributor to the development of hypertension and target organ damage. ${ }^{84}$ Thus, the combination of drugs that target Ang II synthesis (via inhibition of renin or $\mathrm{ACE}$ ) or action (by blockade of $\mathrm{AT}_{1}$ receptors) with hydrochlorothiazide or CCB has a long-standing history of additive BP lowering effects, as well as reduction in CV risk factors. In contrast, effectiveness of the combination of $\beta$-blockers and RAS system inhibitors have been questioned for a long time because of the potential overlap in their mechanisms of action. Indeed, evidence showed that blockade of $\beta$ receptor halts RAS activity by reducing renin release, whereas inhibition of RAS decreased sympathetic nervous activity. ${ }^{85-89}$ However, an increasing body of evidence testifies that in hypertensive patients, nebivolol, in doses ranging from 5 to $40 \mathrm{mg}$ /day, offers an additional BP lowering effect when it was administered in a combination therapy or as an add-on drug to the ongoing therapy with ACEI or ARB. ${ }^{90-93}$ Part of the favorable outcomes for the combination therapy could be attributable to the possibility that nebivolol may ameliorate the increase in plasma renin activity ${ }^{94,95}$ induced by elimination of the negative feedback on renin release mediated by blockade of $\mathrm{AT}_{1}$ receptors. ${ }^{96}$ Increased Ang II observed with ARB treatment may also lead to "aldosterone escape", ${ }^{96}$ and a reduction in aldosterone with the nebivolol therapy has been noted. ${ }^{94,95}$ Furthermore, in contrast to the added hydrochlorothiazide, little or no effect was shown on glucose metabolism and lipid profile in hypertensive patients with prediabetes when nebivolol was added on the background of ACEI or ARB initiating treatment. ${ }^{90}$ Consistently, several randomized studies demonstrated a favorable or neutral effect of nebivolol in patients with dysglycemia. ${ }^{97-101}$

We here review data from the first, and to the best of our knowledge only, study on the efficacy and safety of nebivolol and valsartan in a FDC in hypertensive patients. ${ }^{102}$ The results from this phase 3, randomized, double-blind, placebo-controlled, multicentre study were recently published in the Lancet and were commented on in editorial coverage focusing on hypertension as the biggest contributor to global morbidity and mortality. ${ }^{103}$
In this study, hypertensive adult patients with BP lower than $180 / 110 \mathrm{mmHg}$ were randomly assigned to 4 weeks of double-blind treatment with nebivolol and valsartan FDC (5 and $80 \mathrm{mg} /$ day, 5 and $160 \mathrm{mg} /$ day, or 10 and $160 \mathrm{mg}$ /day), nebivolol ( $5 \mathrm{mg}$ /day or $20 \mathrm{mg} /$ day), valsartan $(80 \mathrm{mg} /$ day or $160 \mathrm{mg} /$ day), or placebo. After the first month, the doses were doubled for the next 4 weeks. After 8 weeks of receiving the respective treatment, it was observed that the reductions in diastolic and systolic BP from baseline, as well as the percentage of patients responding to treatment or achieving BP target goal $(<140 / 90 \mathrm{mmHg}$ in nondiabetics and $<130 / 80 \mathrm{mmHg}$ in diabetics), were greater in the highest FDC (20 and $320 \mathrm{mg} /$ day) when compared with the highest doses of monotherapy, nebivolol $40 \mathrm{mg} /$ day or valsartan $320 \mathrm{mg} /$ day, respectively. A lower-dose combination also showed more favorable outcomes when compared with the respective monotherapy doses. Importantly, the rates of treatment-emerged adverse events were comparable across the treatment groups with the exception of the highest nebivolol dose (40 mg/day). Thus, the placebo-like adverse event profiles of both nebivolol ${ }^{68}$ and valsartan ${ }^{104}$ shown in previous studies have been maintained in the FDC as well. In addition, a high response to placebo in Hispanic and elderly patients, as well as the relatively small number of elderly participants, prevented a critical conclusion of the combination efficacy for these subgroups of patients. Nevertheless, the results of this study suggest that FDC of nebivolol and valsartan offer better BP efficacy and comparable tolerability to monotherapies. In accord with potential better adherence to the single-pill treatment, the study outcomes underline that these combinations should be consider as a safe and effective treatment for hypertensive patients.

\section{Consideration for nebivolol/valsartan combination in the treatment of target organ disease}

An increasing body of evidence suggests that target organ damage depends more on central than peripheral arterial pressure. ${ }^{105}$ In that regard, both nebivolol and valsartan have been shown to reduce central BP and central pulse pressure. ${ }^{52,72,106,107}$ In contrast to nebivolol, despite a similar reduction in brachial artery pressure in patients with uncomplicated hypertension, metoprolol ${ }^{105}$ and atenolol ${ }^{52,107}$ affected neither aortic pulse pressure nor augmentation index, which are important hemodynamic parameters particularly in the elderly population, in whom arterial compliance is already affected. Pulse wave velocity, as a measure of aortic stiffness, was similarly reduced by nebivolol and atenolol or 
metoprolol, and the difference in central pressure may have mirrored a favorable effect on wave reflection as a result of less reduction in heart rate and peripheral vasodilatory effect by nebivolol. Yet in another study, the EFFORT study, with predominantly African-American patients with type 2 diabetes and hypertension who are treated with maximally tolerated doses of RAS blockade, nebivolol did not offer a significant reduction in aortic BP over metoprolol. ${ }^{92}$ Thus, further studies are necessary to clarify a difference between nebivolol and traditional $\beta$-blockers with respect to the beneficial effects on central arterial pressure.

A number of smaller studies suggest left ventricular ejection fraction (LVEF) benefits of nebivolol treatment in patients with $\mathrm{HF}^{74,108,109}$ with one study describing an effect similar to that of carvedilol. ${ }^{109}$ Data from an 8 month randomized trial involving elderly patients with HF (mean LVEF, 26\%; N=260) suggest a relative improvement of LVEF by approximately $36 \%$ among the nebivolol-treated patients compared with $19 \%$ in the placebo group. ${ }^{82}$ The Study of the Effects of Nebivolol Intervention on Outcomes and Rehospitalization in Seniors with Heart Failure (SENIORS trial) ${ }^{73}$ addressed for the first time the value of $\beta$-blockers in elderly subjects ( $\geq 70$ years of age). Patients with HF (mean LVEF, 36\%; $\mathrm{N}=2,128$ ) and a mean follow-up duration of 21 months demonstrated that nebivolol treatment was associated with a significantly lower risk for all-cause mortality or CV-related hospital admission compared with placebo treatment $(31.3 \%$ versus $35.3 \%$; $P=0.039$ ). Of interest is the finding that the greatest benefits were found in women. ${ }^{73}$ The positive results achieved with nebivolol in the SENIORS trial led to the inclusion of nebivolol as one of four $\beta$-blockers recommended for HF in the 2008 guidelines of the European Society of Cardiology. ${ }^{10 ; 111}$

In patients with congestive HF, enhanced activity of both renin angiotensin and sympathetic system activities contribute to the evolution of the syndrome. Accordingly, a large body of clinical trials has shown the benefits of both $\beta$-blockers and RAS inhibitors in patients with cardiac remodeling or HF. The results of the Valsartan in Heart Failure Trial (Val-HeFT) ${ }^{112}$ and the Valsartan in Acute Myocardial Infarction (VALIANT) ${ }^{113}$ trial showed that valsartan is an effective treatment for patients with HF and in patients with postmyocardial infarction. On the basis of the results of the SENIOR study, nebivolol is safe and effective in elderly patients with HF, some of whom have mildly reduced or preserved ejection fraction. ${ }^{73,75,76}$ Taking into account the limited effectiveness of traditional RAS inhibitors in the treatment of HF with preserved ejection fraction, particularly in women, ${ }^{40}$ these results suggests a great potential of nebivolol in the treatment of these patients. Vinereanu and colleages ${ }^{114}$ compared the effects of 6 months of therapy with either nebivolol or metoprolol on the left ventricular function of hypertensive patients. They found that mean longitudinal early diastolic velocity increased by $16 \%(P<0.05)$ with nebivolol compared with a nonsignificant $9 \%$ change with metoprolol. ${ }^{114}$ In addition, flow propagation velocity increased by $34 \%$ on nebivolol and did not change on metoprolol. ${ }^{114}$ Associated improvements in mean longitudinal displacement and ejection time were only observed in the hypertensive patients randomized to nebivolol treatment. ${ }^{114}$ Because the antihypertensive effect was comparable in both groups of treated subjects, the data suggest a unique action of nebivolol in reducing cardiac stiffness, and possibly cardiac fibrosis. This interpretation is in keeping with our demonstration of improved diastolic relaxation and myocardial fibrosis in a renin-dependent model of hypertension after treatment with nebivolol. ${ }^{56}$ Thus, combination therapy with nebivolol and valsartan may offer additional complementary mechanisms in decreasing afterload, improving coronary artery flow, and remodeling and preventing progression of HF.

Our recent studies ${ }^{115,116}$ on the BP-independent effects of nebivolol on cardiac structure and function of hypertensive rats fed a high-salt diet further promote the idea that nebivolol in combination with RAS blockade would have been more beneficial in preventing salt-related cardiac dysfunction. However, additional studies will be needed to validate these early clinical and experimental findings, as nebivolol did not improve impaired ventricular diastolic function, nor did it reduce left ventricular mass in an experimental model of hypertension induced by high salt feeding. In this experimental hypertension model, neither nebivolol nor Ang II blockade lowers BP, even though it has a significant effect in reversing cardiac collagen deposition. ${ }^{116}$

Consistent with small-scale clinical studies showing that nebivolol prevented contrast-induced nephropathy ${ }^{117,118}$ and improved renal function in the postrevascularization phase in patients with renal artery stenosis, ${ }^{119}$ we demonstrated that nebivolol improved renal blood flow and prevented excessive urinary protein loss, collagen deposition, and associated nitro-oxidative (nitrosative) stress while suppressing plasma renin in salt-loaded spontaneously hypertensive rats. ${ }^{115}$ These studies agree with the demonstration that nebivolol improved proteinuria through reductions in renal nicotinamide adenine dinucleotide phosphate oxidase/ reactive oxygen species and increases in bioavailable NO in a renin-dependent hypertension model. ${ }^{120}$ Valsartan is a powerful antihypertensive and renoprotective drug in an 
experimental model of Ang II-dependent hypertension and renal injury. ${ }^{121}$ It seems that the combination of these two drugs may be advantageous in terms of renoprotection, considering that nebivolol may reduce the reactive increase in renin after Ang II blockade.

In summary, nebivolol, a third-generation $\beta$-blocker, is a potent antihypertensive agent that is essentially devoid of clinically important adverse effects. Distinctive mechanisms of action in terms of hemodynamics, metabolic response, and NO-dependent activation of cardiac and vascular vasodilator and antifibrotic mechanisms make this member of the $\beta$-blocker class unique. Emerging studies in which nebivolol is combined with an ARB in a FDC should be of significant value in terms of increased patient compliance, enhanced BP-lowering actions, and reversal of the adverse cardiorenal and vascular remodeling adaptation to hypertension.

\section{Disclosure}

JV received investigator-initiated support from the Forest Research Institute. CMF has received unrestricted grants from Forest Research in the past and has been a member of their speaker bureau. HP has received grant support for Forest Research and has been a member of their speaker bureau. The authors have no other conflicts of interest to disclose.

\section{References}

1. Kearney PM, Whelton M, Reynolds K, Muntner P, Whelton PK, He J. Global burden of hypertension: analysis of worldwide data. Lancet. 2005;365(9455):217-223.

2. Lawes CM, Vander Hoorn S, Law MR, Elliott P, MacMahon S, Rodgers A. Blood pressure and the global burden of disease 2000. Part II: estimates of attributable burden. J Hypertens. 2006;24(3):423-430.

3. Go AS, Mozaffarian D, Roger VL, et al; American Heart Association Statistics Committee and Stroke Statistics Subcommittee. Executive summary: heart disease and stroke statistics - 2014 update: a report from the American Heart Association. Circulation. 2014;129(3):399-410.

4. Go AS, Mozaffarian D, Roger VL, et al; American Heart Association Statistics Committee and Stroke Statistics Subcommittee. Heart disease and stroke statistics - 2014 update: a report from the American Heart Association. Circulation. 2014;129(3):e28-e292.

5. Prugger C, Keil U, Wellmann J, et al; EUROASPIRE III Study Group. Blood pressure control and knowledge of target blood pressure in coronary patients across Europe: results from the EUROASPIRE III survey. J Hypertens. 2011;29(8):1641-1648.

6. Arnett DK. Transforming cardiovascular health through genes and environment: presidential address at the American Heart Association 2012 Scientific Sessions. Circulation. 2013;127(20):2066-2070.

7. Egan BM, Zhao Y, Axon RN. US trends in prevalence, awareness, treatment, and control of hypertension, 1988-2008. JAMA. 2010;303(20):2043-2050.

8. Lloyd-Jones D, Adams R, Carnethon M, et al. Heart disease and stroke statistics - 2009 update: a report from the American Heart Association Statistics Committee and Stroke Statistics Subcommittee. Circulation. 2009;119(3):e21-181.

9. Basile J, Houston M, Ferrario CM. Treating the cardiometabolic syndrome: an opportunity to provide comprehensive cardiovascular risk reduction. J Cardiometab Syndr. 2006;1(5):358-361.
10. Basile J, Houston M, Ferrario C. Incremental risk-factor reduction improves overall cardiovascular benefit: is it time to abandon the silos? J Clin Hypertens (Greenwich). 2006;8(10):686-688.

11. Ferrario CM. Importance of the renin-angiotensin-aldosterone system (RAS) in the physiology and pathology of hypertension. An overview. Drugs. 1990;39(Supp1 2):1-8.

12. Ferrario CM. New physiological concepts of the renin-angiotensin system from the investigation of precursors and products of angiotensin I metabolism. Hypertension. 2010;55(2):445-452.

13. Chobanian AV, Bakris GL, Black HR, et al; National High Blood Pressure Education Program Coordinating Committee. The Seventh Report of the Joint National Committee on Prevention, Detection, Evaluation, and Treatment of High Blood Pressure: the JNC 7 report. JAMA. 2003;289(19):2560-2572.

14. Bakris GL.A practical approach to achieving recommended blood pressure goals in diabetic patients. Arch Intern Med. 2001;161(22):2661-2667.

15. Black HR, Elliott WJ, Neaton JD, et al. Baseline Characteristics and Early Blood Pressure Control in the CONVINCE Trial. Hypertension. 2001;37(1):12-18.

16. Cushman WC, Ford CE, Cutler JA, et al; ALLHAT Collaborative Research Group. Success and predictors of blood pressure control in diverse North American settings: the antihypertensive and lipidlowering treatment to prevent heart attack trial (ALLHAT). J Clin Hypertens (Greenwich). 2002;4(6):393-404.

17. Mancia G, Fagard R, Narkiewicz K, et al; Task Force Members. 2013 ESH/ESC Guidelines for the management of arterial hypertension: the Task Force for the management of arterial hypertension of the European Society of Hypertension (ESH) and of the European Society of Cardiology (ESC). J Hypertens. 2013;31(7):1281-1357.

18. Mancia G, Fagard R, Narkiewicz K, et al. 2013 ESH/ESC guidelines for the management of arterial hypertension: the Task Force for the Management of Arterial Hypertension of the European Society of Hypertension (ESH) and of the European Society of Cardiology (ESC). Eur Heart J. 2013;34(28):2159-2219.

19. Byrd JB, Zeng C, Tavel HM, et al. Combination therapy as initial treatment for newly diagnosed hypertension. Am Heart J. 2011;162(2):340-346.

20. Fogari R, Zoppi A, Ferrari I, Mugellini A, Preti P, Derosa G. Time to achieve blood pressure goal with a combination versus a conventional monotherapy approach in hypertensive patients with metabolic syndrome. Clin Exp Hypertens. 2010;32(5):245-250.

21. Gradman AH, Parisé H, Lefebvre P, Falvey H, Lafeuille MH, Duh MS. Initial combination therapy reduces the risk of cardiovascular events in hypertensive patients: a matched cohort study. Hypertension. 2013; 61(2):309-318.

22. Wald DS, Law M, Morris JK, Bestwick JP, Wald NJ. Combination therapy versus monotherapy in reducing blood pressure: meta-analysis on 11,000 participants from 42 trials. Am J Med. 2009;122(3):290-300.

23. Chalmers J, Arima H, Harrap S, Touyz RM, Park JB. Global survey of current practice in management of hypertension as reported by societies affiliated with the International Society of Hypertension. J Hypertens. 2013;31(5):1043-1048.

24. Jamerson K, Weber MA, Bakris GL, et al; ACCOMPLISH Trial Investigators. Benazepril plus amlodipine or hydrochlorothiazide for hypertension in high-risk patients. N Engl J Med. 2008;359(23):2417-2428.

25. Julius S, Kjeldsen SE, Weber M, et al; VALUE trial group. Outcomes in hypertensive patients at high cardiovascular risk treated with regimens based on valsartan or amlodipine: the VALUE randomised trial. Lancet. 2004;363(9426):2022-2031.

26. Patel A, MacMahon S, Chalmers J, et al; ADVANCE Collaborative Group. Effects of a fixed combination of perindopril and indapamide on macrovascular and microvascular outcomes in patients with type 2 diabetes mellitus (the ADVANCE trial): a randomised controlled trial. Lancet. 2007;370(9590):829-840.

27. PROGRESS Collaborative Group. Randomised trial of a perindoprilbased blood-pressure-lowering regimen among 6,105 individuals with previous stroke or transient ischaemic attack. Lancet. 2001;358(9287):1033-1041. 
28. Ferrario CM, Panjabi S, Buzinec P, Swindle JP. Clinical and economic outcomes associated with amlodipine/renin-angiotensin system blocker combinations. Ther Adv Cardiovasc Dis. 2013;7(1):27-39.

29. Gerbino PP, Shoheiber O. Adherence patterns among patients treated with fixed-dose combination versus separate antihypertensive agents. Am J Health Syst Pharm. 2007;64(12):1279-1283.

30. Tejada T, Fornoni A, Lenz O, Materson BJ. Combination therapy with renin-angiotensin system blockers: will amlodipine replace hydrochlorothiazide? Curr Hypertens Rep. 2007;9(4):284-290.

31. Frishman WH. Beta-Adrenergic blockers: a 50-year historical perspective. Am J Ther. 2008;15(6):565-576.

32. Bakris G. An in-depth analysis of vasodilation in the management of hypertension: focus on adrenergic blockade. J Cardiovasc Pharmacol. 2009;53(5):379-387.

33. Carlberg B, Samuelsson O, Lindholm LH. Atenolol in hypertension: is it a wise choice? Lancet. 2004;364(9446):1684-1689.

34. Law MR, Morris JK, Wald NJ. Use of blood pressure lowering drugs in the prevention of cardiovascular disease: meta-analysis of 147 randomised trials in the context of expectations from prospective epidemiological studies. BMJ. 2009;338:b1665.

35. Lindholm LH, Carlberg B, Samuelsson O. Should beta blockers remain first choice in the treatment of primary hypertension? A meta-analysis. Lancet. 2005;366(9496):1545-1553.

36. James PA, Oparil S, Carter BL, et al. 2014 evidence-based guideline for the management of high blood pressure in adults: report from the panel members appointed to the Eighth Joint National Committee (JNC 8). JAMA. 2014;311(5):507-520.

37. Dahlöf B, Devereux RB, Kjeldsen SE, et al; LIFE Study Group. Cardiovascular morbidity and mortality in the Losartan Intervention For Endpoint reduction in hypertension study (LIFE): a randomised trial against atenolol. Lancet. 2002;359(9311):995-1003.

38. ALLHAT Officers and Coordinators for the ALLHAT Collaborative Research Group. The Antihypertensive and Lipid-Lowering Treatment to Prevent Heart Attack Trial. Major outcomes in high-risk hypertensive patients randomized to angiotensin-converting enzyme inhibitor or calcium channel blocker vs diuretic: The Antihypertensive and LipidLowering Treatment to Prevent Heart Attack Trial (ALLHAT). JAMA. 2002;288(23):2981-2997.

39. Waagstein F, Hjalmarson A, Varnauskas E, Wallentin I. Effect of chronic beta-adrenergic receptor blockade in congestive cardiomyopathy. $\mathrm{Br}$ Heart J. 1975;37(10):1022-1036.

40. Jessup M. The heart failure paradox: an epidemic of scientific success. Presidential Address at the American Heart Association 2013 Scientific Sessions. Circulation. 2014;129(25):2717-2722.

41. Pedersen ME, Cockcroft JR. The vasodilatory beta-blockers. Curr Hypertens Rep. 2007;9(4):269-277.

42. Leenen FH. Possible significance of the pharmacological differentiation of beta-blockers for therapy of hypertension. Br J Clin Pharmacol. 1979;7(S2)(Suppl 2):173S-184S.

43. Messerli FH, Grossman E. beta-Blockers in hypertension: is carvedilol different? Am J Cardiol. 2004;93(9A):7B-12B.

44. Münzel T, Gori T. Nebivolol: the somewhat-different beta-adrenergic receptor blocker. J Am Coll Cardiol. 2009;54(16):1491-1499.

45. Caplin B, Leiper J. Endogenous nitric oxide synthase inhibitors in the biology of disease: markers, mediators, and regulators? Arterioscler Thromb Vasc Biol. 2012;32(6):1343-1353.

46. Ma L, Gul R, Habibi J, et al. Nebivolol improves diastolic dysfunction and myocardial remodeling through reductions in oxidative stress in the transgenic (mRen2) rat. Am J Physiol Heart Circ Physiol. 2012; 302(11):H2341-H2351.

47. de Groot AA, Mathy MJ, van Zwieten PA, Peters SL. Antioxidant activity of nebivolol in the rat aorta. $J$ Cardiovasc Pharmacol. 2004;43(1):148-153.

48. Mason RP, Kubant R, Jacob RF, Walter MF, Boychuk B, Malinski T. Effect of nebivolol on endothelial nitric oxide and peroxynitrite release in hypertensive animals: Role of antioxidant activity. J Cardiovasc Pharmacol. 2006;48(1):862-869.
49. Tarighi B, Kurum T, Demir M, Azcan SN. The effects of nebivolol on fibrinolytic parameters in mild and moderate hypertensive patients. Can J Cardiol. 2007;23(8):651-655.

50. Agabiti Rosei E, Rizzoni D. Metabolic profile of nebivolol, a beta-adrenoceptor antagonist with unique characteristics. Drugs. 2007;67(8):1097-1107.

51. Kamp O, Sieswerda GT, Visser CA. Comparison of effects on systolic and diastolic left ventricular function of nebivolol versus atenolol in patients with uncomplicated essential hypertension. Am J Cardiol. 2003;92(3):344-348.

52. Dhakam Z, Yasmin, McEniery CM, Burton T, Brown MJ, Wilkinson IB. A comparison of atenolol and nebivolol in isolated systolic hypertension. J Hypertens. 2008;26(2):351-356.

53. Van de Water A, Janssens W, Van Neuten J, et al. Pharmacological and hemodynamic profile of nebivolol, a chemically novel, potent, and selective beta 1-adrenergic antagonist. J Cardiovasc Pharmacol. 1988;11(5): $552-563$.

54. Sorrentino SA, Doerries C, Manes C, et al. Nebivolol exerts beneficial effects on endothelial function, early endothelial progenitor cells, myocardial neovascularization, and left ventricular dysfunction early after myocardial infarction beyond conventional $\beta 1$-blockade. $J \mathrm{Am}$ Coll Cardiol. 2011;57(5):601-611.

55. Aragón JP, Condit ME, Bhushan S, et al. Beta3-adrenoreceptor stimulation ameliorates myocardial ischemia-reperfusion injury via endothelial nitric oxide synthase and neuronal nitric oxide synthase activation. J Am Coll Cardiol. 2011;58(25):2683-2691.

56. Zhou X, Ma L, Habibi J, et al. Nebivolol improves diastolic dysfunction and myocardial remodeling through reductions in oxidative stress in the Zucker obese rat. Hypertension. 2010;55(4):880-888.

57. Broeders MA, Doevendans PA, Bekkers BC, et al. Nebivolol: a third-generation beta-blocker that augments vascular nitric oxide release: endothelial beta(2)-adrenergic receptor-mediated nitric oxide production. Circulation. 2000;102(6):677-684.

58. Dawes M, Brett SE, Chowienczyk PJ, Mant TG, Ritter JM. The vasodilator action of nebivolol in forearm vasculature of subjects with essential hypertension. Br J Clin Pharmacol. 1999;48(3):460-463.

59. Tzemos N, Lim PO, MacDonald TM. Nebivolol reverses endothelial dysfunction in essential hypertension: a randomized, double-blind, crossover study. Circulation. 2001;104(5):511-514

60. Galetta F, Franzoni F, Magagna A, et al. Effect of nebivolol on QT dispersion in hypertensive patients with left ventricular hypertrophy. Biomed Pharmacother. 2005;59(1-2):15-19.

61. Wassertheil-Smoller S, Blaufox MD, Oberman A, et al. Effect of antihypertensives on sexual function and quality of life: the TAIM Study. Ann Intern Med. 1991;114(8):613-620.

62. Fogari R, Zoppi A, Corradi L, Mugellini A, Poletti L, Lusardi P. Sexual function in hypertensive males treated with lisinopril or atenolol: a cross-over study. Am J Hypertens. 1998;11(10):1244-1247.

63. Brixius K, Middeke M, Lichtenthal A, Jahn E, Schwinger RH. Nitric oxide, erectile dysfunction and beta-blocker treatment (MR NOED study): benefit of nebivolol versus metoprolol in hypertensive men. Clin Exp Pharmacol Physiol. 2007;34(4):327-331.

64. Boydak B, Nalbantgil S, Fici F, et al. A Randomised Comparison of the Effects of Nebivolol and Atenolol with and without Chlorthalidone on the Sexual Function of Hypertensive Men. Clin Drug Investig. 2005;25(6):409-416.

65. Van Bortel LM, Bulpitt CJ, Fici F. Quality of life and antihypertensive effect with nebivolol and losartan. Am J Hypertens. 2005;18(8):1060-1066.

66. Greathouse M. Nebivolol efficacy and safety in patients with stage I-II hypertension. Clin Cardiol. 2010;33(4):E20-E27.

67. Saunders E, Smith WB, DeSalvo KB, Sullivan WA. The efficacy and tolerability of nebivolol in hypertensive African American patients. J Clin Hypertens (Greenwich). 2007;9(11):866-875.

68. Weiss RJ, Saunders E, Greathouse M. Efficacy and tolerability of nebivolol in stage I-II hypertension: a pooled analysis of data from three randomized, placebo-controlled monotherapy trials. Clin Ther. 2011;33(9):1150-1161. 
69. Neutel JM, Smith DH, Gradman AH. Adding nebivolol to ongoing antihypertensive therapy improves blood pressure and response rates in patients with uncontrolled stage I-II hypertension. J Hum Hypertens. 2010;24(1):64-73.

70. von FJ, Faulhaber HD. [Nebivolol, a beta blocker of the 3rd generation: modern therapy of arterial hypertension. Results of a multicenter observation study]. Praxis (Bern 1994). 2001;90:435-441.

71. Mahmud A, Feely J. Beta-blockers reduce aortic stiffness in hypertension but nebivolol, not atenolol, reduces wave reflection. $\mathrm{Am} \mathrm{J}$ Hypertens. 2008;21(6):663-667.

72. Polónia J, Barbosa L, Silva JA, Bertoquini S. Different patterns of peripheral versus central blood pressure in hypertensive patients treated with $\beta$-blockers either with or without vasodilator properties or with angiotensin receptor blockers. Blood Press Monit 2010;15(5):235-239.

73. Flather MD, Shibata MC, Coats AJ, et al; SENIORS Investigators. Randomized trial to determine the effect of nebivolol on mortality and cardiovascular hospital admission in elderly patients with heart failure (SENIORS). Eur Heart J. 2005;26(3):215-225.

74. Nodari S, Metra M, Dei Cas L. Beta-blocker treatment of patients with diastolic heart failure and arterial hypertension. A prospective, randomized, comparison of the long-term effects of atenolol vs. nebivolol. Eur $J$ Heart Fail. 2003;5(5):621-627.

75. Ghio S, Magrini G, Serio A, et al; SENIORS investigators. Effects of nebivolol in elderly heart failure patients with or without systolic left ventricular dysfunction: results of the SENIORS echocardiographic substudy. Eur Heart J. 2006;27(5):562-568.

76. van Veldhuisen DJ, Cohen-Solal A, Böhm M, et al; SENIORS Investigators. Beta-blockade with nebivolol in elderly heart failure patients with impaired and preserved left ventricular ejection fraction: Data From SENIORS (Study of Effects of Nebivolol Intervention on Outcomes and Rehospitalization in Seniors With Heart Failure). $\mathrm{Am}$ Coll Cardiol. 2009;53(23):2150-2158

77. Signorovitch JE, Samuelson TM, Ramakrishnan K, et al. Persistence with nebivolol in the treatment of hypertension: a retrospective claims analysis. Curr Med Res Opin. 2012;28(4):591-599.

78. Mazza A, Gil-Extremera B, Maldonato A, Toutouzas T, Pessina AC Nebivolol vs amlodipine as first-line treatment of essential arterial hypertension in the elderly. Blood Press. 2002;11(3):182-188.

79. Punzi H, Lewin A, Lukić T, Goodin T, Wei Chen. Efficacy and safety of nebivolol in Hispanics with stage I-II hypertension: a randomized placebo-controlled trial. Ther Adv Cardiovasc Dis. 2010;4(6):349-357.

80. Ko DT, Hebert PR, Coffey CS, Sedrakyan A, Curtis JP, Krumholz HM. Beta-blocker therapy and symptoms of depression, fatigue, and sexual dysfunction. JAMA. 2002;288(3):351-357.

81. Ko DT, Hebert PR, Coffey CS, et al. Adverse effects of beta-blocker therapy for patients with heart failure: a quantitative overview of randomized trials. Arch Intern Med. 2004;164(13):1389-1394.

82. Edes I, Gasior Z, Wita K. Effects of nebivolol on left ventricular function in elderly patients with chronic heart failure: results of the ENECA study. Eur J Heart Fail. 2005;7(4):631-639.

83. Weiss RJ, Weber MA, Carr AA, Sullivan WA. A randomized, double-blind, placebo-controlled parallel-group study to assess the efficacy and safety of nebivolol, a novel beta-blocker, in patients with mild to moderate hypertension. $J$ Clin Hypertens (Greenwich). 2007;9(9):667-676.

84. Ferrario CM. Addressing the theoretical and clinical advantages of combination therapy with inhibitors of the renin-angiotensin-aldosterone system: antihypertensive effects and benefits beyond BP control. Life Sci. 2010;86(9-10):289-299.

85. Grassi G. Counteracting the sympathetic nervous system in essential hypertension. Curr Opin Nephrol Hypertens. 2004;13(5):513-519.

86. Mancia G, Grassi G. The autonomic nervous system and hypertension. Circ Res. 2014;114(11):1804-1814.

87. Parati G, Esler M. The human sympathetic nervous system: its relevance in hypertension and heart failure. Eur Heart J. 2012;33(9): 1058-1066.
88. Shanks J, Herring N. Peripheral cardiac sympathetic hyperactivity in cardiovascular disease: role of neuropeptides. Am J Physiol Regul Integr Comp Physiol. 2013;305(12):R1411-R1420.

89. Zimmerman BG, Sybertz EJ, Wong PC. Interaction between sympathetic and renin-angiotensin system. J Hypertens. 1984;2(6):581-587.

90. Deedwania P, Shea J, Chen W, Brener L. Effects of add-on nebivolol on blood pressure and glucose parameters in hypertensive patients with prediabetes. J Clin Hypertens (Greenwich). 2013;15(4):270-278.

91. Weber MA, Basile J, Stapff M, Khan B, Zhou D. Blood pressure effects of combined $\beta$-blocker and angiotensin-converting enzyme inhibitor therapy compared with the individual agents: a placebo-controlled study with nebivolol and lisinopril. J Clin Hypertens (Greenwich). 2012;14(9):588-592.

92. Briasoulis A, Oliva R, Kalaitzidis R, et al. Effects of nebivolol on aortic compliance in patients with diabetes and maximal renin angiotensin system blockade: the EFFORT study. J Clin Hypertens (Greenwich). 2013;15(7):473-479.

93. Weiss RJ, Stapff M, Lin Y. Placebo effect and efficacy of nebivolol in patients with hypertension not controlled with lisinopril or losartan: a phase IV, randomized, placebo-controlled trial. Am J Cardiovasc Drugs. 2013;13(2):129-140.

94. Blumenfeld JD, Sealey JE, Mann SJ, et al. Beta-adrenergic receptor blockade as a therapeutic approach for suppressing the renin-angiotensin-aldosterone system in normotensive and hypertensive subjects. Am J Hypertens. 1999;12(5):451-459.

95. Chan TY, Woo KS, Nicholls MG. The application of nebivolol in essential hypertension: a double-blind, randomized, placebo-controlled study. Int J Cardiol. 1992;35(3):387-395.

96. Athyros VG, Mikhailidis DP, Kakafika AI, Tziomalos K, Karagiannis A. Angiotensin II reactivation and aldosterone escape phenomena in renin-angiotensin-aldosterone system blockade: is oral renin inhibition the solution? Expert Opin Pharmacother. 2007;8(5):529-535.

97. Poirier L, Cléroux J, Nadeau A, Lacourcière Y. Effects of nebivolol and atenolol on insulin sensitivity and haemodynamics in hypertensive patients. J Hypertens. 2001;19(8):1429-1435.

98. Fogari R, Zoppi A, Lazzari P, et al. Comparative effects of nebivolol and atenolol on blood pressure and insulin sensitivity in hypertensive subjects with type II diabetes. J Hum Hypertens. 1997;11(11):753-757.

99. Kaiser T, Heise T, Nosek L, Eckers U, Sawicki PT. Influence of nebivolol and enalapril on metabolic parameters and arterial stiffness in hypertensive type 2 diabetic patients. $J$ Hypertens. 2006;24(7):1397-1403.

100. Peter P, Martin U, Sharma A, Dunne F. Effect of treatment with nebivolol on parameters of oxidative stress in type 2 diabetics with mild to moderate hypertension. J Clin Pharm Ther. 2006;31(2):153-159.

101. Ladage D, Reidenbach C, Rieckeheer E, Graf C, Schwinger RH, Brixius K. Nebivolol lowers blood pressure and increases weight loss in patients with hypertension and diabetes in regard to age. J Cardiovasc Pharmacol. 2010;56(3):275-281.

102. Giles TD, Weber MA, Basile J, et al; NAC-MD-01 Study Investigators. Efficacy and safety of nebivolol and valsartan as fixed-dose combination in hypertension: a randomised, multicentre study. Lancet. 2014;383(9932):1889-1898.

103. Waeber B, Feihl F. Nebivolol and valsartan: useful treatment for hypertension? Lancet. 2014;383(9932):1864-1866.

104. Makani H, Bangalore S, Supariwala A, Romero J, Argulian E, Messerli FH. Antihypertensive efficacy of angiotensin receptor blockers as monotherapy as evaluated by ambulatory blood pressure monitoring: a meta-analysis. Eur Heart J. 2014;35(26):1732-1742.

105. Tomlinson LA, Selvarajah V, Wilkinson IB. Rate-limiting step: can different effects of antihypertensives on central blood pressure be translated into outcomes? Hypertension. 2011;57(6):1047-1048.

106. Kampus P, Serg M, Kals J, et al. Differential effects of nebivolol and metoprolol on central aortic pressure and left ventricular wall thickness. Hypertension. 2011;57(6):1122-1128. 
107. Koumaras C, Tziomalos K, Stavrinou E, et al. Effects of reninangiotensin-aldosterone system inhibitors and beta-blockers on markers of arterial stiffness. J Am Soc Hypertens. 2014;8(2):74-82.

108. Brehm BR, Wolf SC, Görner S, Buck-Müller N, Risler T. Effect of nebivolol on left ventricular function in patients with chronic heart failure: a pilot study. Eur J Heart Fail. 2002;4(6):757-763.

109. Lombardo RM, Reina C, Abrignani MG, Rizzo PA, Braschi A, De Castro S. Effects of nebivolol versus carvedilol on left ventricular function in patients with chronic heart failure and reduced left ventricular systolic function. Am J Cardiovasc Drugs. 2006;6(4):259-263.

110. Dickstein K, Cohen-Solal A, Filippatos G, et al; ESC Committee for Practice Guidelines (CPG). ESC Guidelines for the diagnosis and treatment of acute and chronic heart failure 2008: the Task Force for the Diagnosis and Treatment of Acute and Chronic Heart Failure 2008 of the European Society of Cardiology. Developed in collaboration with the Heart Failure Association of the ESC (HFA) and endorsed by the European Society of Intensive Care Medicine (ESICM). Eur Heart J. 2008;29(19):2388-2442.

111. Dickstein K, Cohen-Solal A, Filippatos G, et al; ESC Committee for Practice Guidelines (CPG). ESC guidelines for the diagnosis and treatment of acute and chronic heart failure 2008: the Task Force for the diagnosis and treatment of acute and chronic heart failure 2008 of the European Society of Cardiology. Developed in collaboration with the Heart Failure Association of the ESC (HFA) and endorsed by the European Society of Intensive Care Medicine (ESICM). Eur J Heart Fail. 2008;10(10):933-989.

112. Cohn JN. Improving outcomes in congestive heart failure: Val-HeFT. Valsartan in Heart Failure Trial. Cardiology. 1999;91(Suppl 1):19-22.

113. Pfeffer MA, McMurray JJ, Velazquez EJ, et al; Valsartan in Acute Myocardial Infarction Trial Investigators. Valsartan, captopril, or both in myocardial infarction complicated by heart failure, left ventricular dysfunction, or both. N Engl J Med. 2003;349(20):1893-1906.
114. Vinereanu D, Gherghinescu C, Ciobanu AO, et al. Reversal of subclinical left ventricular dysfunction by antihypertensive treatment: a prospective trial of nebivolol against metoprolol. J Hypertens. 2011;29(4):809-817.

115. Varagic J, Ahmad S, Brosnihan KB, et al. Salt-induced renal injury in spontaneously hypertensive rats: effects of nebivolol. Am J Nephrol. 2010;32(6):557-566.

116. Varagic J, Ahmad S, Voncannon JL, et al. Nebivolol reduces cardiac angiotensin II, associated oxidative stress and fibrosis but not arterial pressure in salt-loaded spontaneously hypertensive rats. J Hypertens. 2012;30(9):1766-1774.

117. Avci E, Yeşil M, Bayata S, Postaci N, Arikan E, Cirit M. The role of nebivolol in the prevention of contrast-induced nephropathy in patients with renal dysfunction. Anadolu Kardiyol Derg. 2011;11(7):613-617.

118. Günebakmaz O, Kaya MG, Koc F, et al. Does nebivolol prevent contrast-induced nephropathy in humans? Clin Cardiol. 2012;35(4):250-254.

119. Duranay M, Kanbay M, Akay H, et al. Nebivolol improves renal function in patients who underwent angioplasty due to renal artery stenosis: a pilot study. Nephron Clin Pract. 2010;114(3):c213-c217.

120. Whaley-Connell A, Habibi J, Johnson M, et al. Nebivolol reduces proteinuria and renal NADPH oxidase-generated reactive oxygen species in the transgenic Ren2 rat. Am J Nephrol. 2009;30(4):354-360.

121. Moniwa N, Varagic J, Ahmad S, et al. Hemodynamic and hormonal changes to dual renin-angiotensin system inhibition in experimental hypertension. Hypertension. 2013;61(2):417-424.

122. Skeberdis VA. Structure and function of beta3-adrenergic receptors. Medicina (Kaunas). 2004;40(5):407-413.
Integrated Blood Pressure Control

\section{Publish your work in this journal}

Integrated Blood Pressure Control is an international, peer-reviewed open-access journal focusing on the integrated approach to managing hypertension and risk reduction. Treating the patient and comorbidities together with diet and lifestyle modification and optimizing healthcare resources through a multidisciplinary team approach constitute key

\section{Dovepress}

features of the journal. This journal is indexed on American Chemical Society's Chemical Abstracts Service (CAS). The manuscript management system is completely online and includes a very quick and fair peerreview system, which is all easy to use. Visit http://www.dovepress.com/ testimonials.php to read real quotes from published authors. 